\title{
STUDI INTENSITAS PENCAHAYAAN TERHADAP PUNCAK PRODUKSI AYAM PETELUR FASE LAYER DI UD. MAHAKARYA FARM BANYUWANGI
}

\section{The Study of Lighting Intensity on The Production Peak of Layer Chicken in UD. Mahakarya Farm Banyuwangi}

\author{
Erfan Kustiawan', Dyah Laksito Rukmi' ${ }^{1}$, Shokhirul Imam ${ }^{1}$, dan Shandy Owen Permadi ${ }^{1}$ \\ 1 Jurusan Peternakan, Politeknik Negeri Jember \\ Email: erfan.kustiawan.polije@gmail.com
}

\begin{abstract}
INTISARI
Studi kasus ini bertujuan untuk mengetahui tingkat pencahayaan yang baik pada ayam petelur fase layer. Pengambilan data dilakukan selama tiga bulan bertempat di UD. Mahakarya Farm Banyuwangi. Sebanyak 4.400 ekor ayam fase layer digunakan dalam penelitian ini. Intensitas pencahayaan yang digunakan yaitu 10 lux pada kandang A dan 15 lux pada kandang B. Rata-rata produksi telur pada hasil studi kasus ini adalah 75,91\% pada kandang A (10 lux) dan 73,57\% pada kandang B (15 lux). Rata-rata berat telur kandang A 59,37 g dan kandang B 59,23 g. Hasil studi menunjukkan bahwa pada usia mulai dari 25 minggu menghasilkan nilai efisiensi produksi lebih baik dengan menggunakan intensitas pencahayaan 10 lux. Pada usia menjelang akhir produksi (38 minggu) penggunaan intensitas pencahayaan 15 lux meningkatkan efisiensi produksi.
\end{abstract}

Kata kunci : Berat Telur, Fase Layer, Intensitas Pencahayaan, Produksi Telur

\begin{abstract}
The objective of this case study was to evaluate good lighting levels in laying hens. The data were collected for three months at UD. Mahakarya Farm Banyuwangi. A total of 4.400 heads of layer chicken were used in this study. The lighting intensityused were 15 lux in cage $A$ and 10 lux in cage $B$. The average of egg production were $75.91 \%$ and $73.57 \%$ for cage $A$ (15 lux) and cage B (10 lux), respectively. The average of egg weight were $59.37 \mathrm{~g}$ and $59.23 \mathrm{gfor}$ cage $A$ (15 lux) and cage $B(10$ lux), respectively. The results of this study presented that layer chicken aged 25 weeks produced better production efficiency values by 10 lux. At the end of production period(38 weeks) increased production efficiency by 15 lux.
\end{abstract}

Keywords: Egg Weight, Layer, Lighting Intensity, Egg Production

\section{PENDAHULUAN}

Puncak produksi ayam petelur adalah masa dimana produksi telur dari ayam sangat tinggi. Puncak produksi biasa dicapai pada umur 26 minggu sampai 29 minggu dan dapat berlangsung sampai 24 minggu. Produksi dapat dikatakan mencapai puncak jika persentase produksi telur (HD) lebih dari 90\% (Rasyaf, 2002). Tercapainya puncak produksi dan dapat bertahan lama menjadi tolok ukur keberhasilan suatu usaha peternakan. Puncak produksi dapat tercapai pada fase layer tidak lepas dari pemeliharaan fase sebelumnya yaitu fase grower dan fase starter.

Faktor yang mempengaruhi tercapainya puncak produksi salah satunya adalah keseragaman. Keseragaman ini tidak hanya untuk berat badan namun juga keseragaman kedewasaan kelamin. Kematangan seksual yang seragam sangat diperlukan agar dapat mencapai puncak produksi dan puncak produksi tersebut dapat berlangsung lama. Agar dapat mencapai keseragaman kedewasaan kelamin yang baik tentunya ada 
tindakan yang harus dilakukan salah satunya adalah program pencahayaan.

Program pencahayaan adalah salah satu yang sangat berpengaruh pada tercapainya puncak produksi karena berhubungan dengan keseragaman kedewasaan kelamin. Adanya pencahayaan (matahari) maupun lampu dapat menstimulsi hipotalamus dan akan diterukan ke kelenjar hipofisa. Kelenjar hipofisa akan mensekresikan 2 hormon yaitu hormon FSH (Folicle Stimulating Hormone) dan LH (Luteinizing Hormone). Hormon FSH berfungsi untuk mematangkan folikel telur sedangkan hormon LH berfungsi untuk menggertak proses ovulasi.

Fase produksi pencahayaan yang baik diberikan maksimal 16 jam dengan intensitas cahaya 10 lux sampai 20 lux (Medion, 2014). Lama pencahayaan dan intensitas cahaya perlu diperhatikan untuk menunjang produksi dari ternak. Pencahayaan masa produksi awalnya berlangsung selama 12 jam berasal dari cahaya matahari, setelah berproduksi pencahayaan akan ditambah sehingga mencapai total 16 jam. Pada penambahan pencahayaan tidak boleh langsung ditambah 4 jam, penambahan cahaya dilakukan bertahap yaitu 1 jam setiap minggunya.

Berdasarkan pernyataan diatas maka program pencahayaan harus diatur mulai dari lama penerangan sampai berapa intensitas cahaya yang diberikan, sehingga dibuatlah penulisan tentang program lama pencahayaan yang sama namun dengan intensitas yang berbeda dan diharapkan penulisan ini dapat bermanfaat bagi mahasiswa ataupun peternak yang mencari informasi tentang program pencahayaan ayam petelur pada fase produksi.

\section{MATERI DAN METODE}

\section{Materi Penelitian}

Pengambilan data dilakukan selama tiga bulan bertempat di UD Mahakarya Farm Banyuwangi, Kabupaten Banyuwangi, Jawa
Timur. Alat yang digunakan dalam studi kasus ini adalah adalah kandang produksi, dan recording produksi telur. Bahan yang digunakan dalam kegiatan Studi Kasus ini adalah ayam petelur fase layer strain Lohman berjumlah 4.400 ekor.

\section{Metode Pelaksanaan}

Studi ini menggunakan metode deskriptif dengan tujuan untuk mengumpulkan informasi secara rinci yang menyangkut tentang program pencahayaan ayam petelur fase layer dengan menggunakan data primer dan sekunder. Data primer diperoleh langsung dari sumber datanya melalui wawancara berupa pencatatan recording, ukuran kandang dan program pencahayaan yang digunakan. Data sekunder diperoleh dari berbagai sumber mengenai program pencahayaan ayam petelur fase layer.

\section{Program Pencahayaan}

Penambahan waktu pencahayaan dilakukan pada minggu ke-25 saat ayam sudah berproduksi telur. Pencahayaan pada siang hari selama 12 jam dan penambahan pencahayaan dilakukan secara bertahap yaitu 1 jam setiap minggunya hingga jumlah pencahayaan mencapai 16 jam. Penambahan pencahayaan pada minggu pertama dilakukan pada pukul 17.00 WIB kemudian pada minggu kedua penambahan dilakukan pukul 05.00 WIB untuk minggu ketiga pada pukul 18.00 WIB dan penambahan terakhir pada pukul 04.00 WIB. Intensitas pencahayaan terdiri dari 15 lux untuk kandang A dan 10 lux untuk kandang B.

\section{Parameter Pengamatan}

\section{Produksi telur per minggu}

Penghitungan produksi telur per minggu dilakukan dengan cara menghitung Hen Day Production terlebih dahulu dengan cara total butir pada saat itu dibagi dengan populasi dikali 100 dan produksi per minggu 
merupakan rataan Hen Day Production selama 1 minggu

$$
\text { Hen Day }=\frac{\text { Total Butir }}{\text { Populasi }} \times 100
$$

\section{Feed egg ratio (FER)}

FER merupakan perbandingan antara ransum yang dikonsumsi ayam untuk menghasilkan sejumlah telur. Rumus dari FER adalah jumlah pakan yang dikonsumsi (kg) dibagi dengan telur yang dihasilkan (kg).

$$
\text { FER }=\frac{\text { Pakan yang dikonsumsi }(\mathrm{kg})}{\text { Telur yang dihasilkan }(\mathrm{kg})}
$$

\section{Berat telur}

Perhitungan berat telur dilakukan dengan cara menghitung total kg telur dibagi dengan total butir dikali 1.000.

\section{Intensita cahaya}

Perhitungan intensitas cahaya mengunakan rumus sebagai berikut:

$$
I=\frac{J L}{L K} \times \text { L } \times \text { F-utilisasi } \times \text { F-depresi }
$$

$\begin{array}{cl}\text { Ket: I } & \text { : Intensitas } \\ \text { JL } & \text { : Jumlah lampu } \\ \text { LK } & : \text { Luas kandang } \\ \text { L } & : \text { Lumen } \\ \text { f-utilasi } & : 0,65 \\ \text { f-depresi } & : 0,9\end{array}$

\section{Pengambilan Data}

Data yang diperoleh dari data primer dan data sekunder akan diolah dan akan dilakukan perhitungan dari setiap parameter selanjutnya akan dilakukan pembahasan secara diskriptif.

\section{HASIL DAN PEMBAHASAN}

\section{Program Pencahayaan}

Program pencahayaan akan berpengaruh terhadap organ reproduksi dari ayam. Pencahayaan yang ada akan mempengaruhi kelenjar-kelenjar ayam petelur sehingga mensekresikan hormon FSH dan LH.

Program pencahayaan pada umumnya fase layer dilakukan pada minggu ke-18 dengan menambah 30 menit pada setiap minggunya sampai total pencahayaan mencapai 16 jam (Medion, 2014), sedangkan di UD. Mahakarya Farm penambahan pencahayaan dilakukan pada saat ayam sudah mulai bertelur yaitu pada minggu ke- 25 .

\section{Intensitas Cahaya}

Pada kandang di UD. Mahakarya Farm menggunakan dua intensitas pencahayaan yang berbeda yaitu kandang dengan intensitas 15 lux (kandang A) dan 10 lux (kandang B). Intensitas yang lebih tinggi akan memberikan ruang yang semakin terang.

Peran intensitas cahaya sangat penting pada program pencahayaan ayam petelur karena berhubungan dengan 2 hormon penting bagi reproduksi ayam petelur yaitu hormon FSH dan LH yang akan mempengaruhi proses ovulasi (Kasiyati, 2018).

\section{Produksi Telur Per Minggu}

Berdasarkan data pada Gambar 1 menunjukan perbedaan rata-rata produksi telur selama 14 minggu terhadap intensitas pencahayaan yang berbeda, yaitu 15 lux (kandang A) dan 10 lux (kandang B). Ratarata produksi telur dengan intensitas pencahayaan 15 lux lebih baik dari 10 lux. Dari Gambar 1 juga dapat dilihat bahwa intensitas pencahayaan 15 lux lebih cepat dalam mencapai puncak produksi daripada 10 lux. Puncak produksi dengan intensitas pencahayaan 15 lux tercapai pada minggu ke31 , sedangkan intensitas pencahayaan 10 lux terpaut 1 minggu yaitu tercapai pada minggu ke-32. Produksi telur dengan intensitas pencahayaan 15 lux lebih tinggi dari 10 lux. Hal ini disebabkan oleh adanya rangsangan terhadap hormon reproduksi dari ayam yaitu hormon FSH dan LH. Kedua hormon tersebut berpengaruh terhadap proses pembentukan 
folikel dan proses ovulasi. Menurut Fauzynasty (2010) intensitas cahaya merangsang pelepasan dan peningkatan suplai FSH, melalui aktivitas ovary mengakibatkan terjadinya ovulasi atau pengeluaran sel telur dan oviposisi peletakkan telur sebelum keluar.

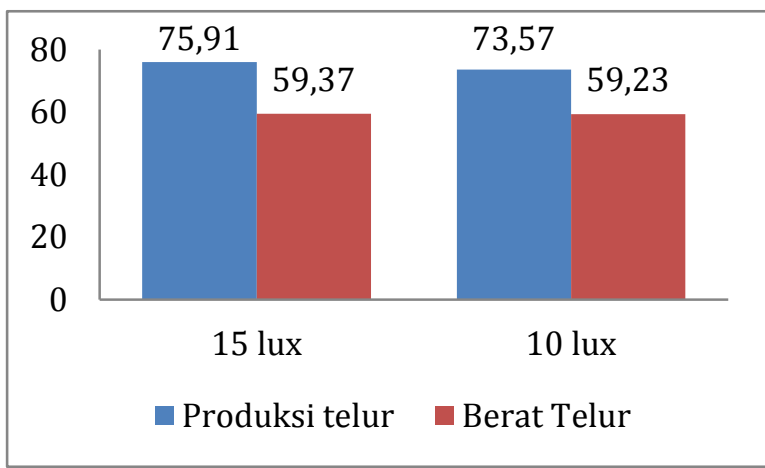

Gambar 1. Grafik produksi dan berat telur pada pemeliharaan pada umur 25 minggu sampai 38 minggu

\section{Berat Telur}

Rata-rata berat telur dari kedua intensitas pencahayaan tidak jauh berbeda, dimana hasil rata-rata berat telur pada intensitas pencahayaan 15 lux sebesar 59,37 g, sedangkan intensitas pencahayaan 10 lux rata-rata berat telur 59,22 g (Gambar 1). Secara umum intensitas cahaya memberikan hasil berat telur yang relatif sama. Berat telur lebih dipengaruhi oleh lama pencahayaan. Fauzynasty (2010) menyatakan bahwa jika penambahan cahaya diberikan berlebihan maka mengakibatkan ukuran telur menjadi lebih kecil dan jika lama pencahayaan yang diberikan kurang maka akan menghasilkan ukuran telur lebih besar.

\section{Feed Egg Ratio (FER)}

Berdasarkan Gambar 2, konversi pakan pada intensitas pencahayaan 15 lux saat awal produksi (minggu ke-25) sangat besar mencapai 18,6 sedangkan pada intensitas pencahayaan 10 lux memiliki konversi pakan yang lebih baik dengan nilai FER 11,0. Namun pada minggu ke-38 FER dengan intensitas pencahayaan 15 lux lebih baik yaitu 1,83 dibandingkan dengan intensitas pencahayaan 10 lux yaitu 2,01.

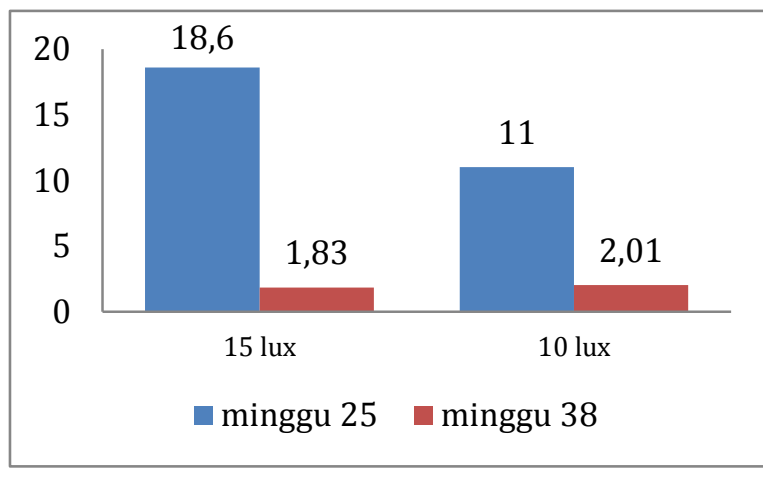

Gambar 2. Grafik FER mengetahui tingkat pencahayaan yang baik untuk ayam petelur fase layer

Intensitas pencahayaan yang lebih tinggi menyebabkan ruangan lebih terang sehingga memudahkan ayam untuk melihat makanan sama seperti pendapat Rasyaf (2002) yang menyatakan bahwa pemberian cahaya pada malam hari memberikan kesempatan ayam lebih mudah menjangkau pakan.

\section{KESIMPULAN}

Penggunaan intensitas pencahayaan 15 lux pada umur awal puncak produksi (25 minggu) menghasilkan produksi telur lebih baik, puncak produksi lebih cepat tercapai, FER lebih rendah, namun menghasilkan berat telur yang relatif sama dengan intensitas pencahayaan 10 lux.

\section{DAFTAR PUSTAKA}

Fauzynasty. 2010. Hubungan Cahaya Terhadap Produktifitas. http://fauzynasty.

blogspot.com/2010/10/hubungan-

cahaya-terhadap-produktifitas.html.

Diakses tanggal 5 April 2019.

Kasiyati. 2018. Peran Cahaya bagi Kehidupan Unggas: Respons Pertumbuhan dan Reproduksi. Buletin Anatomi dan Fisiologi. 3(1):116-125.

Medion. 2014. Pencahayaan Harus di Program dengan Baik. https://info.medion.co.id 
/index.php/artikel-layer/artikel-tatalaksana/1190-pencahayaan-harus-diprogram-dengan-baik. Diakses tanggal 20 April 2019.

Rasyaf, M. 2002. Beternak Ayam Petelur. Penebar Swadaya. Jakarta. 